\title{
Enthalpy of Interaction and Binding Isotherms of Non-ionic Surfactants onto Micellar Amphiphilic Polymers (Amphipols).
}

\author{
C. Diab ${ }^{1}$, F. M. Winnik ${ }^{1, *}$ and C. Tribet ${ }^{2} *$
}

\section{Supporting information.}

\section{Synthesis and characterization of the polymers C22-43 and C45-68}

Materials. Azobisisobutyronitrile (AIBN, 98\%) was recrystallized from methanol. N-Isopropylacrylamide (stabilized, 99\%) was obtained from Acros Organics and was recrystallized from acetone/heptane (4:6). The chain transfer agent, S-1-isobutyl-S'( $\alpha, \alpha$-dimethyl- $\alpha$ "-N-isopropylacetamide)trithiocarbonate ${ }^{\mathrm{i}}$ and the monomers, noctylacrylamide $^{\mathrm{ii}}$ and N-t-BOC-N-(ethylenedioxybis(ethyl)acrylamide ${ }^{\mathrm{iii}}$ were prepared as described previously. 1,4-Dioxane (ACP, ACS Reagent) was distilled over sodium under argon. All other solvents were reagent grade and used as received.

Methods. Proton NMR spectra were recorded on a Bruker AMX-400 (400 MHz). The chemical shifts are referenced to trimethylsilane (TMS). UV/Visible spectra were measured with an Agilent 8452A photodiode array spectrometer. Infrared spectra were recorded on a Bruker Vector 22 equipped with a Harrick MVP ATR cell. Gel permeation chromatography (GPC) was performed with a GPC system consisting of an Agilent 1100 isocratic pump, a set of TSK-gel $\alpha$-M and a TSK-gel $\alpha-3000$ (Tosoh Biosep) columns, a Dawn EOS multi-angle laser light scattering detector (Wyatt Technology Corp.) and an Optilab DSP interferometric refractometer (Wyatt Technology Corp.); injection volume: $100 \mu \mathrm{L}$; flow rate: $0.5 \mathrm{~mL} \mathrm{~min}^{-1}$; eluent: DMF; temperature: $40{ }^{\circ} \mathrm{C}$. The $\mathrm{d} n / \mathrm{dc}$ values were measured with an Optilab DSP interferometric refractometer (Wyatt Technology Corp) used off-line.

Preparation of C22-43. The polymerization was performed in a septum-capped 25 mm x $150 \mathrm{~mm}$ glass tube placed in a First Mate system from Argonaut Technologies. A solution of NIPAM (0.25 g, $2.2 \mathrm{mmol}), \mathrm{N}-\mathrm{t}-\mathrm{BOC}-\mathrm{N}-[($ ethylenedioxybis(ethyl) 
acrylamide] (1.34 g, $4.4 \mathrm{mmol})$, n-octylacrylamide (0.4 g, $2.2 \mathrm{mmol})$ and S-1isobutyl-S'-( $\alpha, \alpha$-dimethyl- $\alpha$ "-N-isopropylacetamide)trithiocarbonate (26 mg, 0.0887 mmol) in dioxane $(10 \mathrm{~mL})$ was degassed for 30 minutes by vigorously bubbling nitrogen. The mixture was heated to $65^{\circ} \mathrm{C}$. Azobis(isobutyronitrile) (AIBN) (2.88 mg, $0.0175 \mathrm{mmol}$ ) was added at once. The polymerization mixture was stirred at $65{ }^{\circ} \mathrm{C}$ for $17 \mathrm{hr}$. It was cooled to room temperature. The solvent was removed by evaporation. The polymer formed was purified by two precipitations from THF into hexanes and dried in vacuo; ${ }^{1} \mathrm{H}$ NMR $\left(\mathrm{CDCl}_{3}, \delta \mathrm{ppm}\right): 0.88\left(3 \mathrm{H}, \mathbf{H}_{3} \mathrm{CC}_{7} \mathrm{H}_{14^{-}}\right), 1.16(6 \mathrm{H}$, $\left.\left(\mathrm{CH}_{3}\right)_{2} \mathrm{CH}^{-}\right) 1.27\left(12 \mathrm{H},-\mathrm{NHCH}_{2}\left(\mathrm{CH}_{2}\right)_{6} \mathrm{CH}_{3}\right), 1.44\left(9 \mathrm{H},\left(\mathrm{CH}_{3}\right)_{3} \mathrm{CO}\right), 1.89$ (2H, BOC$\left.\mathrm{NHCH}_{2}^{-}\right), 3.67\left(8 \mathrm{H}, \mathrm{CH}_{2}\right.$ of the ethylenedioxy group), $4.0\left(1 \mathrm{H},\left(\mathrm{CH}_{3}\right)_{2} \mathrm{CHNHCO}^{-}\right.$ ], $5.4\left(1 \mathrm{H},-\mathrm{NH}^{-}\right)$. The molar mass of this polymer was obtained by GPC analysis (see experimental). The $\mathrm{dn} / \mathrm{dc}$ value of this polymer in $\mathrm{DMF}$ at $40{ }^{\circ} \mathrm{C}$ was 0.088 $\mathrm{cm}^{3} / \mathrm{g}$ at $690 \mathrm{~nm}$.

The N-t-BOC protecting group was removed with trifluoroacetic acid followed by ion exchange with a Dowex 2X8-400 as described previously. ${ }^{\text {iii }}$ Phosphorylcholine groups were linked to the polymer by reductive amination of phosphorylcholine glyceraldehyde ${ }^{\mathrm{iii}}$ following a protocol described previously, ${ }^{\mathrm{iii}}$ yielding the polymer C22-43 which was purified by dialysis against water. It was isolated by lyophilization. ${ }^{1} \mathrm{H}$ NMR $\left(\mathrm{CD}_{3} \mathrm{OD}, \delta \mathrm{ppm}\right): 0.92\left(3 \mathrm{H}, \mathbf{H}_{3} \mathrm{CC}_{7} \mathrm{H}_{14^{-}}\right), 1.16$ $\left(6 \mathrm{H},\left(\mathrm{CH}_{3}\right)_{2} \mathrm{CH}^{-}\right), 1.27\left(12 \mathrm{H},-\mathrm{NHCH}_{2}\left(\mathrm{CH}_{2}\right)_{6} \mathrm{CH}_{3}\right), 2.88-3.2\left(4 \mathrm{H},-\mathrm{CH}_{2} \mathrm{CH}_{2} \mathrm{NHCH}_{2}^{-}\right)$, $3.25\left(9 \mathrm{H},\left(\mathrm{CH}_{3}\right)_{3} \mathrm{~N}^{+}-\right), 3.67\left(8 \mathrm{H}, \mathrm{CH}_{2}\right.$ of ethylenedioxy group), $3.9\left(1 \mathrm{H},\left(\mathrm{CH}_{3}\right)_{2} \mathrm{CH}^{-}\right)$, $4.0\left(2 \mathrm{H},-\mathrm{POCH}_{2} \mathrm{CH}_{2} \mathrm{NHCH}_{2}^{-}\right), 4.3\left[2 \mathrm{H},\left(\mathrm{CH}_{3}\right)_{3} \mathrm{~N}^{+} \mathrm{CH}_{2} \mathrm{CH}_{2} \mathrm{OP}-\right]$; FTIR $\left(v, \mathrm{~cm}^{-1}\right)$ : $1226\left(\mathrm{v}_{\mathrm{as}} \mathrm{PO}_{2}^{-}\right), 966\left(\mathrm{v}_{\mathrm{as}} \mathrm{N}-\mathrm{CH}_{3}\right)$.

Preparation of C45-68. A solution of N-t-BOC-N-[(ethylenedioxybis(ethyl)acrylamide] (0.831 g, $2.75 \mathrm{mnol})$ and $n$-octylacrylamide $(0.168 \mathrm{~g}, 0.92 \mathrm{mmol})$ in 
dioxane $(10 \mathrm{~mL})$ was degassed for 30 minutes by vigorously bubbling of nitrogen through the solution. The mixture was heated to $65{ }^{\circ} \mathrm{C}$. Azobis(isobutyronitrile) (4.6 mg) was added at once. The polymerization mixture was stirred at $65{ }^{\circ} \mathrm{C}$ for $17 \mathrm{hr}$. It was cooled to room temperature. The solvent was removed by evaporation, and the polymer was purified by two precipitations from THF into hexanes and dried in vacuo $\left(1.075\right.$ g). ${ }^{1} \mathrm{H} \quad \mathrm{NMR} \quad\left(\mathrm{CDCl}_{3}, \quad \delta \quad \mathrm{ppm}\right): 0.88 \quad\left(3 \mathrm{H}, \quad \mathbf{H}_{3} \mathrm{CC}_{7} \mathrm{H}_{14}\right), \quad 1.27 \quad(12 \mathrm{H}$, $\left.-\mathrm{NHCH}_{2}\left(\mathrm{CH}_{2}\right)_{6} \mathrm{CH}_{3}\right), 1.44\left(9 \mathrm{H},\left(\mathrm{CH}_{3}\right)_{3} \mathrm{CO}\right), 1.89\left(2 \mathrm{H}, \mathrm{BOC}-\mathrm{NHCH}_{2}-\right), 3.67(8 \mathrm{H}$, $\mathrm{CH}_{2}$ of ethylenedioxy group), $5.4\left(1 \mathrm{H},-\mathrm{NH}^{-}\right)$. The molar mass of this polymer was obtained by GPC analysis (see experimental). The $\mathrm{dn} / \mathrm{dc}$ value of this polymer in was $0.088 \mathrm{~cm}^{3} \mathrm{~g}^{-1}$ at $690 \mathrm{~nm}$.

Deprotection of the amine and reductive amination of phosphorylcholine were performed as described in the case of $\mathrm{C} 22-43$. The resulting polymer was purified by dialysis against water and isolated by lyophilization. ${ }^{1} \mathrm{H}$ NMR $\left(\mathrm{CD}_{3} \mathrm{OD}, \delta \mathrm{ppm}\right): 0.92$ $\left(3 \mathrm{H}, \mathbf{H}_{3} \mathrm{CC}_{7} \mathrm{H}_{14^{-}}\right), 1.27\left(12 \mathrm{H},-\mathrm{NHCH}_{2}\left(\mathrm{CH}_{2}\right)_{6} \mathrm{CH}_{3}\right), 2.88-3.2\left(4 \mathrm{H},-\mathrm{CH}_{2} \mathrm{CH}_{2} \mathrm{NHCH}_{2}^{-}\right)$, $3.25\left(9 \mathrm{H},\left(\mathrm{CH}_{3}\right)_{3} \mathrm{~N}^{+}-\right), 3.67\left(8 \mathrm{H}, \mathrm{CH}_{2}\right.$ of ethylene dioxy group), $4.0(2 \mathrm{H}$, $\left.-\mathrm{POCH}_{2} \mathrm{CH}_{2} \mathrm{NHCH}_{2}-\right), 4.3\left[2 \mathrm{H},\left(\mathrm{CH}_{3}\right)_{3} \mathrm{~N}^{+} \mathrm{CH}_{2} \mathrm{CH}_{2} \mathrm{OP}-\right]$; FTIR $\left(v, \mathrm{~cm}^{-1}\right): 1226\left(v_{\text {as }}\right.$ $\left.\mathrm{PO}_{2}^{-}\right), 966\left(\mathrm{v}_{\mathrm{as}} \mathrm{N}-\mathrm{CH}_{3}\right)$. 


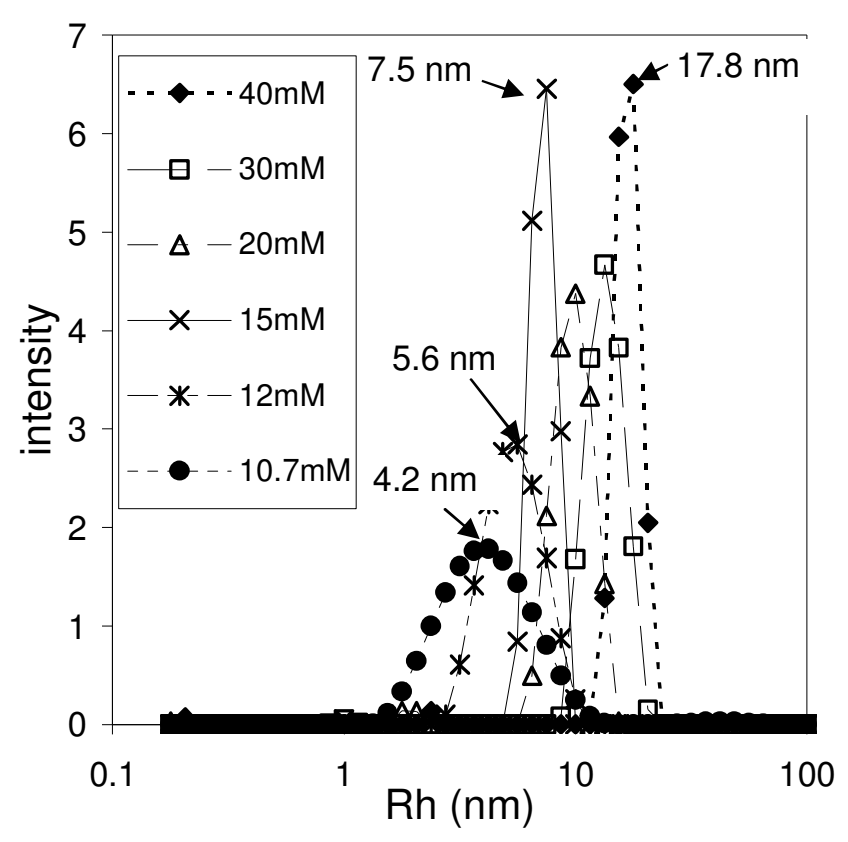

Figure S1: Hydrodynamic radii distributions obtained from DLS measurements carried out with solutions of OTG in $20 \mathrm{mM} \mathrm{NaOH}$-phosphoric acid buffer, $\mathrm{pH}$ 7.0. The concentrations of OTG are listed in the figure

Expression of the enthalpy of mixing

The experimental molar enthalpy measured by ITC upon injecting surfactant micelles into a micellar amphipol solution was expressed as the sum of terms corresponding to the micelle dilution, the disintegration of polymer and of surfactant micelles, and the formation of amphipol/surfactant associates from isolated amphipols and surfactant molecules, as stated in Equation S1, where $N_{s, \text { tot }}$ is the molar amount of total surfactant injected:

$N_{s, \text { tot }} \Delta \mathrm{H}_{\text {exp }}=\Delta \mathrm{H}_{\text {micelle dilution }}+\Delta \mathrm{H}_{\text {surfactant demicellization }}+\Delta \mathrm{H}_{\text {monomer dilution }}+\Delta \mathrm{H}_{\text {polymer dilution }}$ $+\Delta \mathrm{H}_{\text {polymer demicellization }}+\Delta \mathrm{H}_{\text {mixed association }} \quad$ Equation $\mathrm{S} 1$

Among the various enthalpic contributions to $\Delta \mathrm{H}_{\mathrm{exp}}$, one can neglect the enthalpy of dilution of molecules or micelles which, experimentally, were shown to be very small, compared to the other contributions. The term $\Delta \mathrm{H}_{\text {surfactant demicellization }}$ is known experimentally from ITC titrations of surfactant micelles in buffer. Control ITC 
experiments involving titrations of micellar amphipols in buffer indicated that demicellization of the amphipol assemblies does not occur in solution of concentrations higher than $0.5 \mathrm{~g} / \mathrm{L}$. The last term $\Delta \mathrm{H}_{\text {mixed association }}$ which corresponds to the excess enthalpy of mixing when surfactant micelles are mixed with polymer micelles in a given ratio is given by Equation S2, which invokes the regular solution approximation:

$$
\Delta H_{\text {mixed association }}=N \Delta H_{\text {reg }}=N\left[X_{s} X_{p} \beta R T+X_{s} \Delta H_{m i c, s}+X_{p} \Delta H_{m i c, p}\right] \quad \text { Equation }
$$

S2

where $N$ is the number of moles of amphiphiles involved in the association, $X_{S}$ and $\mathrm{X}_{\mathrm{p}}$ $=1-X_{s}$ are the mole fractions of amphiphiles in the mixed associates, $\mathrm{T}$ is the temperature, $\mathrm{R}$ is the universal gas constant, $\Delta \mathrm{H}_{\text {mic,s }}$ and $\Delta \mathrm{H}_{\text {mic,p }}$ are the molar enthalpies of micellization of surfactant and polymer, respectively. From equations S1 and S2 and neglecting the enthalpies of dilution, one can write:

$$
N_{s, t o t} \Delta H_{\text {exp }} \sim-N_{m i c, s} \Delta H_{m i c, s}+\left(N_{s}+N_{p}\right) \Delta H_{r e g}-N_{p} \Delta H_{m i c, p} \quad \text { Equation S3 }
$$

where $N_{s, \text { tot }}$ and $N_{m i c, s}$ are the molar amounts of total surfactant injected and of surfactant injected in the micellar form, respectively, $N_{s}$ is the number of surfactant molecules that enter into associates, and $N_{p}$ is the total molar amount of alkyl groups lined to the amphipols, $X_{s}=N_{s} /\left(N_{p}+N_{s}\right)$ and $X_{p}=N_{p} /\left(N_{s}+N_{p}\right)$. Assuming that all the alkyl groups belonging to the polymer chains enter in micelle formation, irrespective of the presence of detergent, the last term in equation $\mathrm{S} 2\left(\mathrm{~N} . \mathrm{Xp} \Delta \mathrm{H}_{\mathrm{mic}, \mathrm{p}}\right)$ is the exact opposite of the last term in equation $\mathrm{S} 3\left(\Delta \mathrm{H}_{\text {polymer demicellization }}=-N_{p} \Delta \mathrm{H}_{\text {mic,p }}\right)$ 

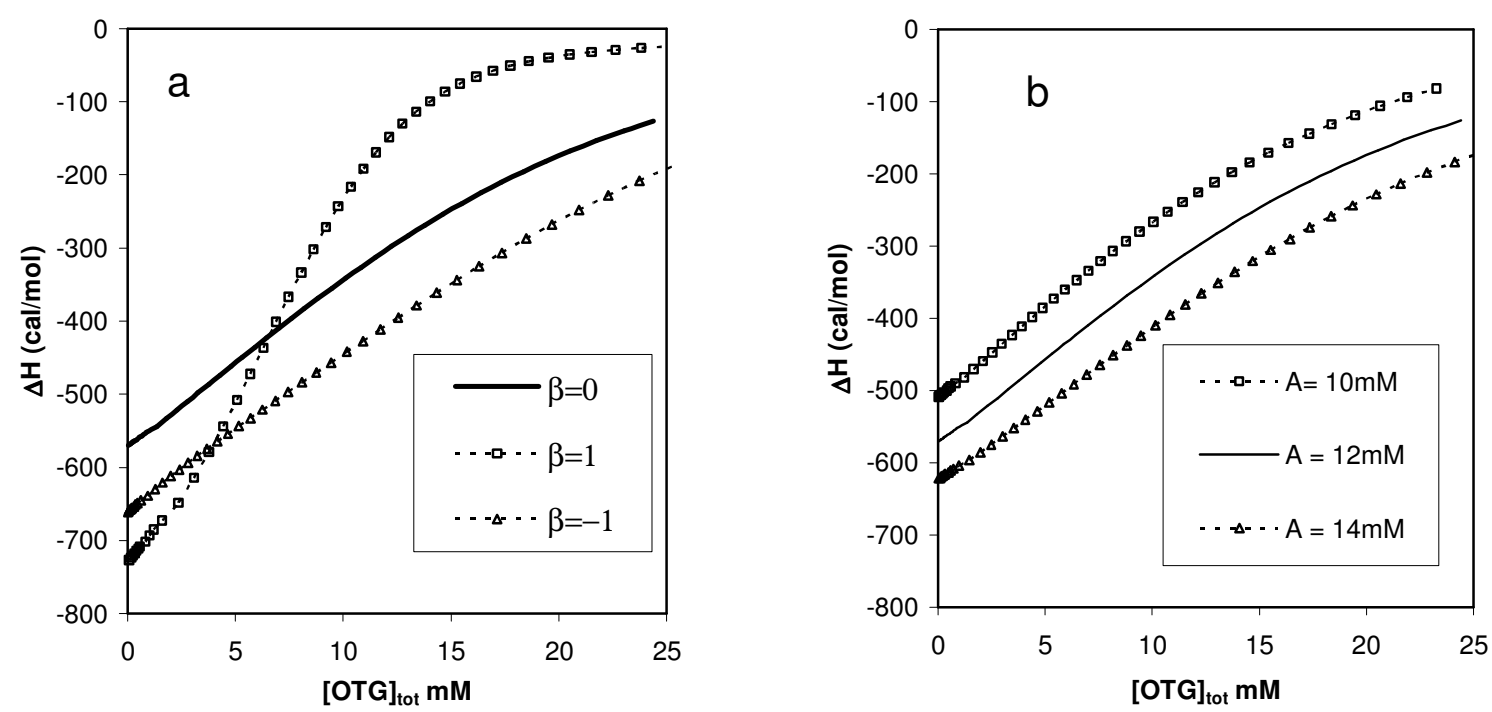

Figure S2: Calculated enthalpy of mixing as a function of the total OTG concentration in the cell for a addition of a $100 \mathrm{mM}$ OTG solution in a solution of A8$35(5 \mathrm{~g} / \mathrm{L})$. Data points were obtained from equations 3 and 5 as detailed in the text, with the values of the parameters $A$ and $\beta$ listed in the figure.

\section{References}

i. $\quad$ Kujawa, P.; Segui, F.; Shaban, S.; Diab, C.; Okada, Y.; Tanaka, F.; Winnik, F. M. Macromolecules 2006, 39, 341.

ii. Effing, J. J.; McLennan, I. J.; van Os, N. M.; Kwak, J. C. T. J. Phys. Chem. 1994, 98, 12397.

iii. Miyazawa, K.; Winnik, F. M. Macromolecules, 2002, 35, 2440. 